\title{
Quinazoline Derivatives as Anticancer Agents: QSAR, Molecular Docking and in silico Pharmacokinetic Prediction
}

\author{
Siddharth Jitendrakumar Modi, Vithal Madhvarao Kulkarni* \\ Department of Pharmaceutical Chemistry, Poona College of Pharmacy, Bharati Vidyapeeth (Deemed to be University), Pune- 411038, \\ Maharashtra, INDIA.
}

\begin{abstract}
Context: Molecular target specific treatment for the cancer is different from the conventional chemotherapy and radiotherapy in terms of selectivity and specificity towards the cancer cells. Amongst the different molecular targets for cancer, EGFR tyrosine kinase is considered more promising molecular target for discovery and development of the novel anticancer agents. EGFR overexpression and deregulation or mutation are observed in the different kinds of epithelial cancer namely non-small-cell lung cancer, colon cancer, breast cancer etc. Aim: To carry out structure based drug design (SBDD) and ligand based drug design (LBDD) approaches on quinazoline derivatives as EGFR inhibitors. Methods: A set of 25 compounds was used to correlate the structural parameter(s) with its inhibitory effect on EGFR using 3D-QSAR (CoMFA and CoMSIA) technique. Further, the molecular docking simulation was carried out to recognize the interaction of ligands with the active site of EGFR. All the compounds from the dataset were aligned using the distill alignment method. Post alignment of the dataset, CoMFA and CoMSIA analysis were executed. Moreover, pharmacokinetic (ADMET) predictions of all the quinazoline derivatives were carried out using admetSAR tool. Results: CoMFA and CoMSIA both the models were found statistically significant with values of the cross-validation correlation coefficient $\left(\mathrm{q}^{2}\right)$ as 0.757 and 0.524 respectively and conventional correlation coefficient $\left(r^{2}\right)$ as 0.925 and 0.855 respectively. Further, the molecular docking simulation revealed that all the quinazoline derivatives were situated at the same place as that of the standard drug erlotinib with reasonable penetration at the active site of the EGFR. Conclusion: Results of this work provide the information regarding the structure activity relationship and important structure requirements for the interaction of compounds at the active site of the receptor. This information provides a hint for the design of novel analogs as EGFR tyrosine kinase inhibitors.
\end{abstract}

Key words: ErbB, EGFR, 3D-QSAR, Contour maps, Molecular docking, ADMET.

\section{INTRODUCTION}

Epidermal growth factor receptor (EGFR) is part of ErbB family of tyrosine kinase receptors. It is a type of transmembrane tyrosine kinase receptor which is responsible for the modulation of growth factor signaling. ${ }^{1}$ The ErbB family of RTK consists of four receptors namely ErbB-1 (EGFR), ErbB-2 (HER 2), ErbB-3 and ErbB-4., ${ }^{2,3}$ These receptors are present in the cytoplasmic membrane and consist of the hydrophobic transmembrane region and an intra-cytoplasmic tyrosine kinase domain. ${ }^{4}$ Ligand dependent and ligand independent both of the mechanisms play an important role in overexpression of EGFR receptor in cancer. However, growth factor of EGF family binds to ErbB receptor and activate the receptor. These growth factors were generated by the same cells, which express ErbB receptor (autocrine secretion) or by neighboring cells (paracrine secretion). 5,6 EGF growth factors are divided into three
Submission Date: 08-06-2018; Revision Date: 29-08-2018; Accepted Date: 23-10-2018

DOI: 10.5530/ijper.52.4s.112 Correspondence:

Dr. Vithal M. Kulkarni, Professor Emeritus, Department of Pharmaceutical Chemistry, Poona College of Pharmacy, Bharati Vidyapeeth (Deemed to be University), Erandwane,

Pune - 411038, Maharashtra, INDIA.

Phone: +91-9890802623

E-mail: vmkulkarni60@gmail. com

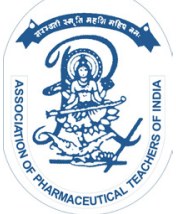

www.ijper.org 
main groups; (i) EGF, transforming growth factor $\alpha$ (TGF- $\alpha$ ) and amphiregulin (AR) that binds to the epidermal growth factor receptor. ${ }^{7}$ (ii) Epiregulin (EPR), heparin-binding growth factor (HB-EGF) and betacellulin (BTC) binds to the ErbB-4 along with EGFR. (iii) Neuregulins (NRGs) which can be bifurcated into two main sub groups; namely sub group of NRG 1 and NRG 2; sub group of NRG 3 and NRG 4. Sub group of NRG 1 and NRG 2 binds to ErbB-3 and ErbB-4 receptors. Sub group of NRG 3 and NRG 4 binds to the ErbB-4 receptor. ${ }^{8-11}$ The overexpression of EGFR receptor is reported in many type of cancer namely carcinoma of lungs ( $80 \%$ of cases), glioblastoma (50\% of cases), epithelial head and neck tumours $(100 \%$ of cases), colon cancer and breast cancer. ${ }^{12}$ Therefore, EGFR has been well studied receptor for anticancer drug development. After identification of EGFR as cancer target, a number of anticancer agents against the EGFR receptor have been developed such as gefitinib, erlotinib, afatinib, brigatinib, neratinib, vandetanib, lapatinib, osimertinib, icotinib etc. ${ }^{13-19}$ The structures of approved EGFR inhibitors are depicted in Figure 1. Other than this, monoclonal antibody inhibitors such as panitumumab, nimotuzumab, matuzumab etc. were also developed..$^{20-22}$ Despite, the discovery and development of a large number of EGFR inhibitors, still intrinsic or acquired resistance was observed in the cancer patients who are treated with EGFR targeted drugs. ${ }^{23}$ So, there is a constant need for the discovery of novel inhibitors targeted to the epidermal growth factor receptor. The crystal structures of EGFR receptors have been reported. So, the structure-based drug design (SBDD) i.e., molecular docking, as well as ligand-based drug

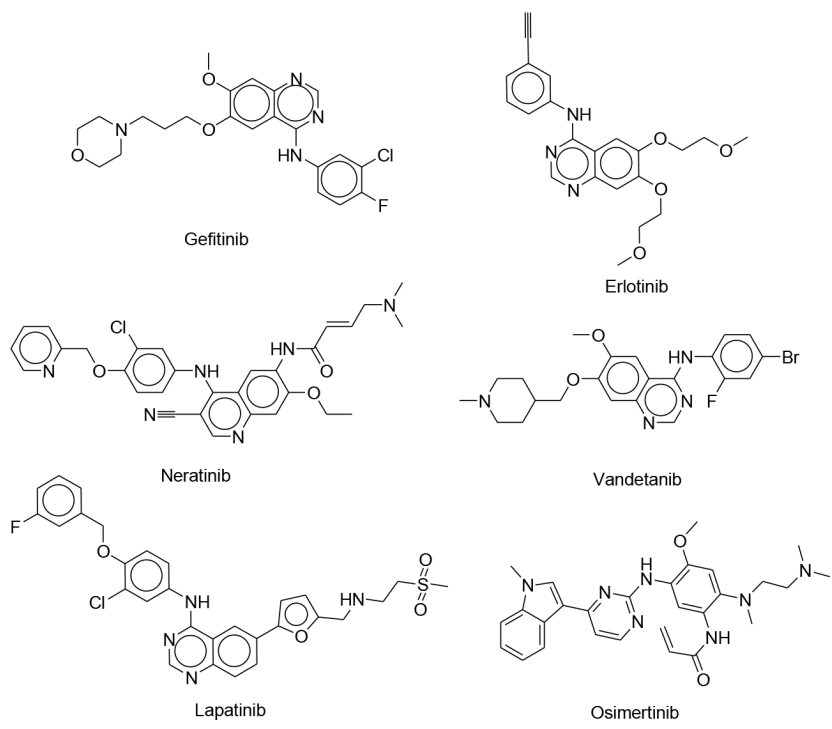

Figure 1: Chemical structures of approved EGFR receptor inhibitors. design approach (LBDD) i.e., QSAR and pharmacophore modeling are possible for identification of novel EGFR receptor inhibitors. In the current study, we have carried out both the method molecular docking and 3D-QSAR, for the identification of structural requirement and correlation of structural parameter (independent variable) with its biological activity (dependent variable) respectively. The selective and potent EGFR receptor inhibitors were outlined in the literature. ${ }^{24}$ For, the correlation of structure with the inhibitory activity, three-dimensional quantitative structure activity relationship (QSAR) was carried out. 3D-QSAR was performed using comparative molecular field analysis (CoMFA) and comparative molecular similarity indices analysis (CoMSIA). ${ }^{25}$ CoMFA is the type of 3D-QSAR technique where steric and electrostatic fields were utilized as independent variables against the biological activity of compounds. Whereas, CoMSIA is an improved method of CoMFA in which other than steric and electrostatic, hydrophobic, H-bond donor and $\mathrm{H}$-bond acceptor were used as independent variables to correlate structure with the biological activity. ${ }^{26}$ In the current study, 3D QSAR was performed on the 25 quinazoline analogs. Depending upon the, 3D-QSAR results, the contour maps for steric, electrostatic, hydrophobic, $\mathrm{H}$-bond acceptor and $\mathrm{H}$-bond donor were generated. Further, the molecular docking study was carried out using crystal structure of EGFR to find the structural characteristics which are required for interaction of inhibitors at the active site of the receptor. Moreover, ADMET and the molecular property predictions of all the derivatives were reported. Based on the information gathered from contour maps analysis and molecular docking, the regions were identified surrounding the molecule and the modification can be carried out for the improvement of the biological activity against EGFR receptor.

\section{MATERIALS AND METHODS Data preparation}

We have collected the quinazoline derivatives as EGFR tyrosine kinase inhibitors for this study from the literature. ${ }^{24}$ The selected quinazoline derivatives were bifurcated into approximate $70 \%$ of the training set (17 derivatives) and approximate $30 \%$ of the test set (8 derivatives). Test set derivatives have a range of activity similar to that of training set. ${ }^{27}$ Derivatives present in the both the set (training set and test set) were used for the generation and validation of QSAR model respectively. The $\mathrm{IC}_{50}$ value of all the derivatives was transformed into $\mathrm{pIC}_{50}\left(-\log \mathrm{IC}_{50}\right)$ value. These transformed $\mathrm{pIC}_{50}$ values were employed as dependent variable for the QSAR study. Table 1 depicts 


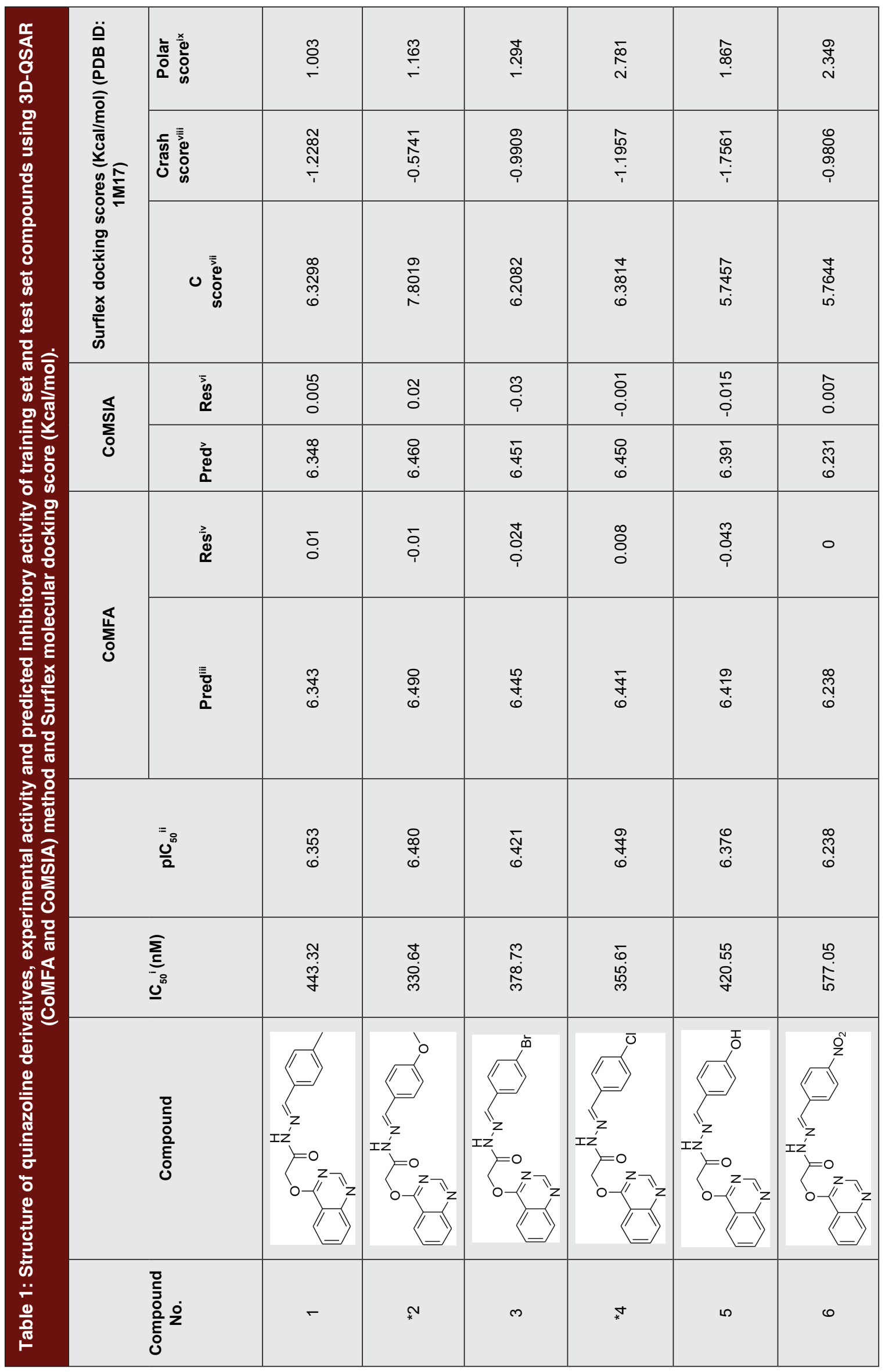









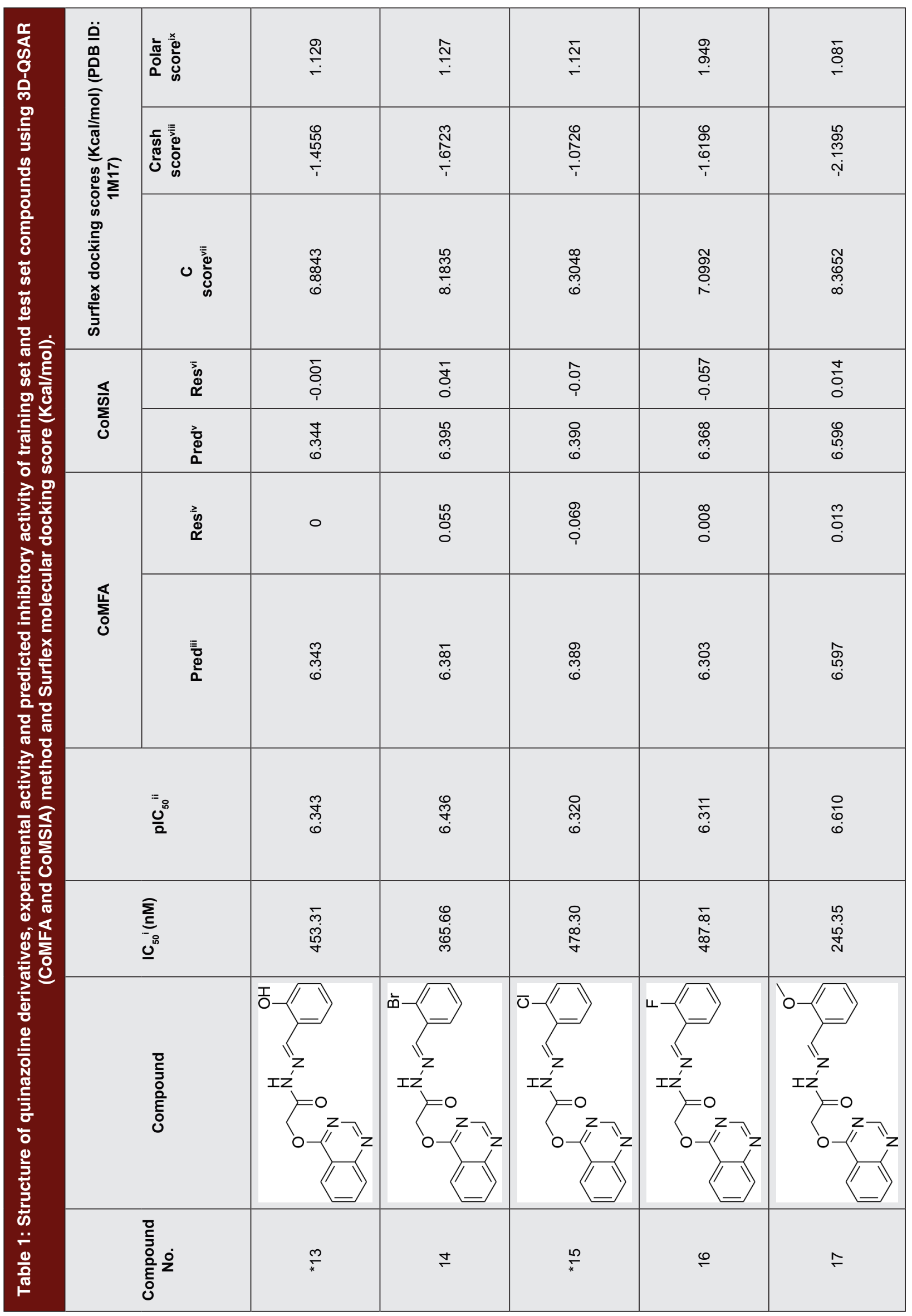




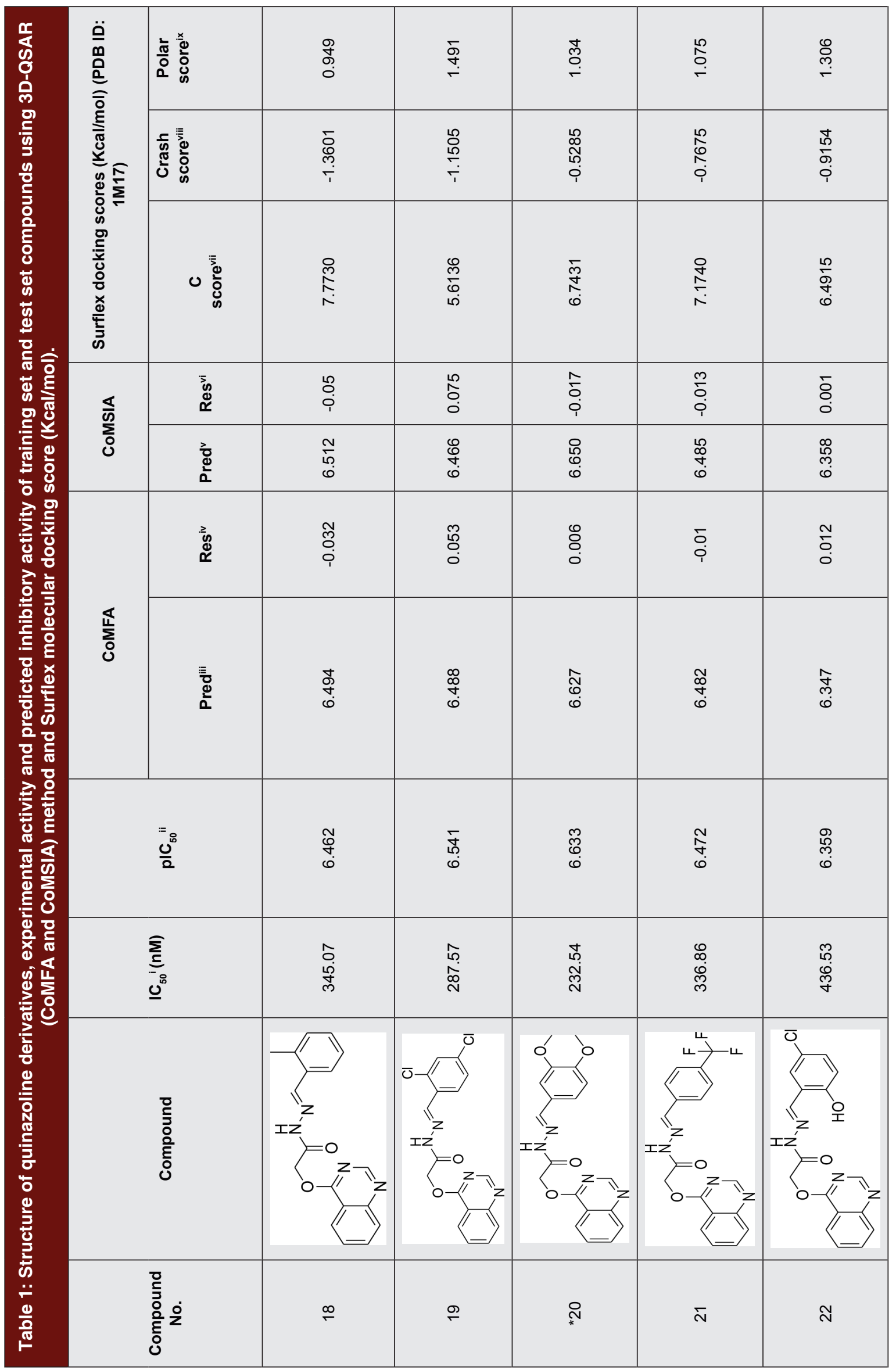




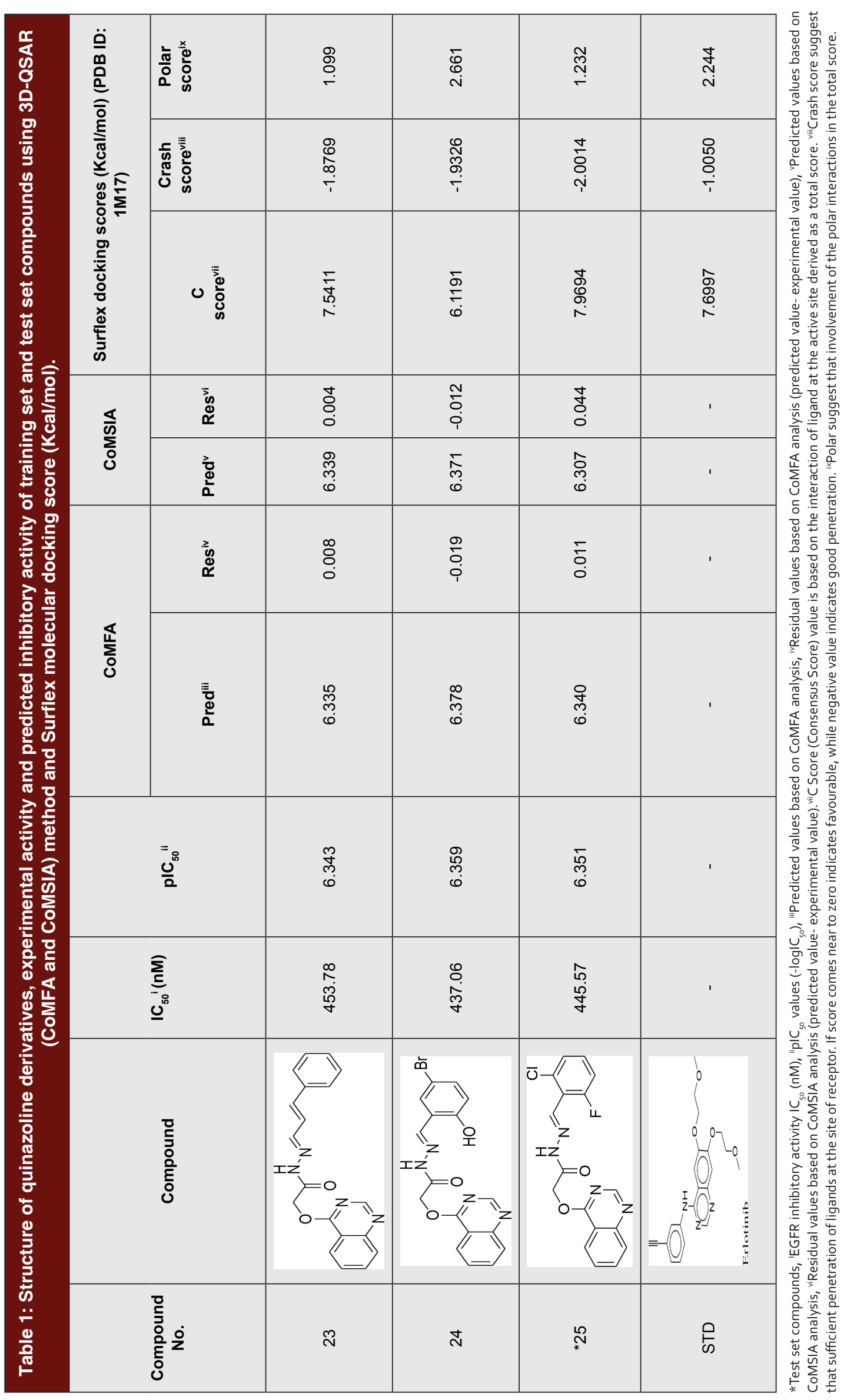


the structure of all the quinazoline derivatives along with their biological activity against EGFR receptor.

\section{Computational study and alignment of database}

SYBYL-X 2.0 from Tripos Inc. was accessed to perform 3D-QSAR study. Sketch function from SYBYL software was utilized for building the 3D structures of all the quinazoline derivatives. Gasteiger Huckel $(\mathrm{GH})$ charges along with the TRIPOS force field was applied to all designed derivatives for the structure optimization process. ${ }^{28}$ Further, energy minimization was carried out by Powell conjugated gradient algorithm method. Alignment of dataset is crucial step in QSAR study. So, Distill alignment was performed for the same. Alignment was executed by selecting highly potent quinazoline derivative from the dataset as template structure. ${ }^{29}$ Figure 2 and Figure 3 represent common fragment of EGFR inhibitors and all aligned compounds respectively.

\section{CoMFA and CoMSIA model}

Three-dimensional cubic lattice with $2 \AA$ grid space, which was extended to $4 \AA$ for the aligned dataset in $\mathrm{X}$, $\mathrm{Y}$ and $\mathrm{Z}$ three axis, was set by default for calculation of CoMFA and CoMSIA fields. Here, carbon atom withSp $\mathrm{p}^{3}$ spin, radius of $1.52 \AA$ and +1 charge was used as probe atom under CoMFA analysis. In CoMFA analysis, for the derivation of steric and electrostatic fields, interaction energy was determined using the Tripos force field. While, $\pm 30 \mathrm{kcal} / \mathrm{mol}$ cut-off value was set for steric as well as electrostatic fields. At the lattice intersection, Lennard-Jones and Columbic potentials were utilized. ${ }^{30}$

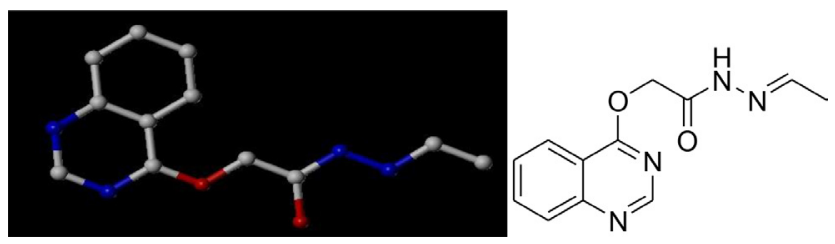

Figure 2: The common structure of EGFR kinase inhibitors for alignment of database to perform QSAR study.

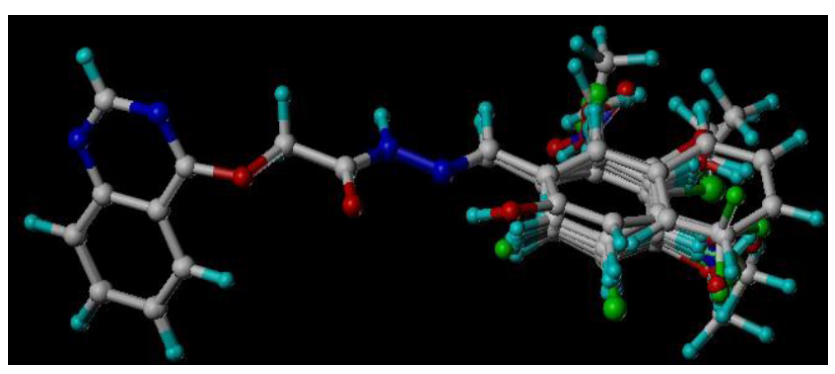

Figure 3: Alignment of dataset for 3D-QSAR (CoMFA and CoMSIA) study.
For the CoMSIA study, five descriptors namely steric, electrostatic, hydrophobic, H-bond donor and $\mathrm{H}$-bond acceptor, were used. For hydrophobic, H-bond donor and $\mathrm{H}$-bond acceptor probe atom with +1 charge was used by default. While all other parameters are similar as in CoMFA model, only the value of attenuation factor $(\alpha)$ was set to 0.3 for ease of functioning.

\section{PLS analysis}

PLS (Partial Least Square) is an extension of multiple linear regression analysis (MLR) method. 3D-QSAR models were built using PLS study. Here, the values of CoMFA and CoMSIA were utilized as independent variables, while EGFR tyrosine kinase inhibitory activity values were used as dependent variable to correlate structural parameter and inhibitory activity. If the QSAR models are developed using the optimum number of components with a high value of cross-validation coefficient $\left(\mathrm{q}^{2}\right)$ and low standard errors, then the chances of over fitted models are very less. In cross-validation coefficient $\left(\mathrm{q}^{2}\right)$ method, one compound was removed from the dataset and by use of all other compounds, model was generated. The activity of elided compound was predicted using developed QSAR model. If the methods give the values of $\mathrm{q}^{2}>0.5$ and $\mathrm{r}^{2}>0.616$, then the models are assumed as acceptable. ${ }^{31}$ It is calculated by the following equation:

$$
\mathrm{q}^{2}=1-\frac{£\left(\mathrm{Y}_{\text {predicted }}-\mathrm{Y}_{\text {observed }}\right)}{£\left(\mathrm{Y}_{\text {observed }}-\mathrm{Y}_{\text {mean }}\right)}
$$

The optimum number of component (ONC) was used to calculate the value of $r_{n c v}^{2}$ (Non-cross validation correlation coefficient). Further, to check the robustness of the developed model bootstrap analysis was undertaken. It is a method where random compounds were selected from entire data set. This method was undertaken many times (minimum 100 times for more accuracy). In each run, some compounds were elided from the dataset while some compounds were included in the dataset. The value of $\mathrm{r}_{\mathrm{bs}}^{2}$ from bootstrap analysis and $\mathrm{r}_{\mathrm{cv}}^{2}$ from cross-validation were determined. ${ }^{25}$

\section{Predictive correlation coefficient $\left(\mathbf{r}^{2}{ }_{\text {pred }}\right)$}

Eight test set derivatives were utilized for the calculation of predictability of developed QSAR model. It is calculated by the following equation:

$$
r_{\text {pred }}^{2}=\frac{(S D-P R E S S)}{S D}
$$

Here, the sum of squared deviation between biological activity of test set and mean activity of training set was 
represented as SD. While, the sum of squared deviations between experimental and predicted activity values for each derivative in the test set was represented PRESS. ${ }^{32}$

\section{Molecular docking simulation}

In the present study, the docking simulation was carried out to recognize the active site conformation and important interactions, which are responsible for ligandreceptor complex stability. Here, Surflex-Dock module present in the SYBYL-X 2.0, was used for the molecular docking simulation. The X-RAY crystal structure of EGFR tyrosine kinase was retrieved from Protein Data Bank (PDB ID: 1M17, X-RAY resolution-2.6 $\AA$ ). The structures of quinazoline derivatives were built in SYBYL-X software. ${ }^{33}$ Gasteiger Huckel (GH) charges along with the TRIPOS force field were applied to all designed derivatives for structure optimization process. Further, energy minimization was carried out using Powell's conjugated gradient algorithm method. After incorporation of protein, preparation of the protein was carried out. For that purpose from the crystal structure, co-crystallized ligand and all the water molecules were removed; further hydrogens were inserted and side chain was fixed. TRIPOS force field was used for the minimization of structure. The interaction efficiency of the compounds with the receptor was expressed in $\mathrm{kcal} /$ mol units by Surflex-Dock score. For the identification of the interaction between ligand and protein, the best pose was incorporated into the molecular area. ${ }^{34,35} \mathrm{Molec}-$ ular Computer Aided Design (MOLCAD) programme was used to visualize ligands interaction with receptor. ${ }^{36}$

\section{Pharmacokinetic (ADMET) and molecular properties prediction of quinazoline derivatives}

In the past, anticancer drugs were withdrawn from the market during the Phase I-III clinical trial or at Phase IV because of insufficient ADMET (absorption, distribution, metabolism. excretion and toxicity) parameters. Further, adverse effect associated with the anticancer agents may be dependent directly or indirectly on the pharmacokinetic parameters. Despite this, an in-silico ADMET prediction provides support during lead optimization process and prevents withdrawal of molecules during clinical trials. Online software admetSAR was used for the prediction of pharmacokinetic parameters. ${ }^{37}$ Moreover, molecular properties (Lipinski's rule of five (RO5)) such as molecular weight, $\mathrm{H}$-bond donor, $\mathrm{H}$-bond acceptor and Lipophilicity values of all the quinazoline analogs were also determined and reported in Table 4.

\section{RESULTS AND DISCUSSION CoMFA model}

Table 2: Statistical parameters obtained by CoMFA and CoMSIA.

\begin{tabular}{|c|c|c|}
\hline PLS analysis parameters & CoMFA & CoMSIA \\
\hline $\mathrm{r}_{\text {LOO }}^{2}\left(\mathrm{q}^{2}\right)$ & 0.757 & 0.524 \\
\hline$r_{n c v}^{2}$ & 0.925 & 0.855 \\
\hline SEE & 0.031 & 0.043 \\
\hline ONC & 6 & 6 \\
\hline$F$ value & 36.814 & 27.748 \\
\hline Steric field contribution & 3.064 & 0.862 \\
\hline Electrostatic field contribution & 1.891 & 1.774 \\
\hline Hydrophobic field contribution & - & 1.223 \\
\hline H-bond donor field contribution & - & 0.316 \\
\hline $\begin{array}{l}\text { H-bond acceptor field } \\
\text { contribution }\end{array}$ & - & 0.510 \\
\hline$r_{b s}^{2}$ & 0.967 & 0.941 \\
\hline SEE $_{b s}$ & 0.019 & 0.026 \\
\hline $\mathrm{r}_{\mathrm{CV}}^{2}$ & 0.631 & 0.478 \\
\hline Test set $r^{2}\left(r^{2}{ }_{\text {pred }}\right)$ & 0.703 & 0.511 \\
\hline
\end{tabular}

CoMFA was generated using steric and electrostatic fields. As the first step, PLS study was undertaken by use of "leave-one-out (LOO)". The $\mathrm{q}^{2}$ value was found to be 0.757 with 6 optimum numbers of components. The same 6 components along with column filtering set to 2.0 were used to calculate the value of conventional correlation coefficient $\left(\mathrm{r}^{2}{ }_{\text {ncv }}\right)$. The value of $\mathrm{r}_{\text {ncv }}^{2}$ was found to be 0.925, F value as 36.814 and SEE (Standard Error of Estimate) as 0.031. The steric and electrostatic field value were found to be 3.065 and 1.891 respectively. Table 2 depicts the statistical parameters obtained by development of CoMFA model. The results of cross-validation coefficient $r_{c v}^{2}(0.716)$ and bootstrap analysis $r_{b s}^{2}(0.967)$ supported the reliability of developed QSAR model. Experimental and predicted activity values of training set compounds and test set compounds are already depicted in Table 1 . Figure 4(A, B) depicts the correlation of experimental and predicted activity values of training and test set compounds.

\section{CoMSIA model}

CoMSIA provides details of steric, electrostatic, hydrophobic, H-bond donor and $\mathrm{H}$-bond acceptor fields. CoMSIA was undertaken by similar training and test set compounds as that of CoMFA following the successful results of CoMFA. The value of $\mathrm{q}^{2}$ was found to be 0.524 with 6 optimum numbers of components. To calculate the conventional correlation coefficient, same 6 components and column filtering as 2.0 were used. The value of $\mathrm{r}_{\text {ncv }}^{2}$ was found to be 0.855 . The contribution values of steric, electrostatic, hydrophobic, H-bond donor and 

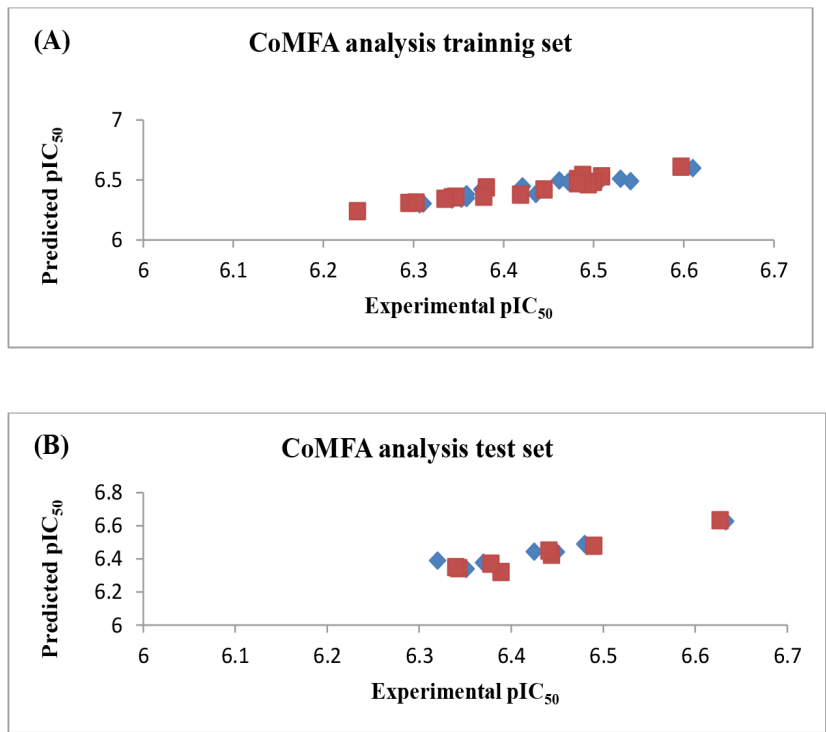

Figure 4: Plot of experimental and predicted activities of the training and the test set compounds based on CoMFA model.
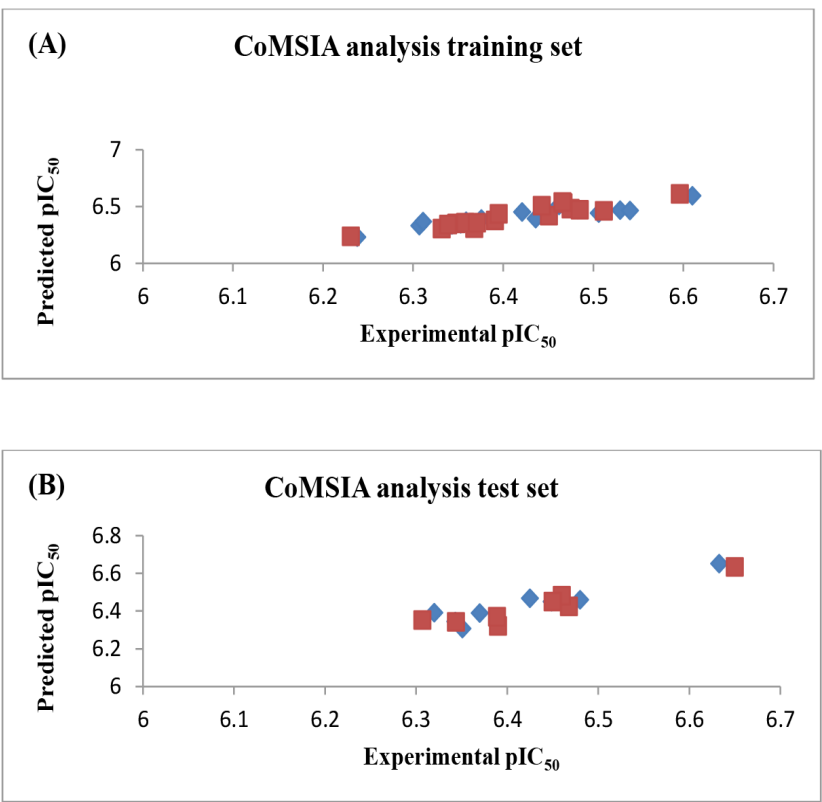

Figure 5: Plot of experimental and predicted activities of the training and the test set compounds based on CoMSIA model.

H-bond acceptor were found to be $0.862,1.774,1.223$, 0.316 and 0.510 respectively. Further, bootstrap analysis $\left(r^{2}=0.941\right)$ supported the quality of the developed CoMSIA model. Internal reliability in the dataset was checked by cross-validation (leave half out) method. The $\mathrm{r}_{\mathrm{cv}}{ }_{\mathrm{w}}$ was found to be 0.478 . The values of $\mathrm{r}_{\mathrm{bs}}{ }$ and $\mathrm{SEE}_{\mathrm{bs}}$ were found to be 0.941 and 0.026 respectively. Experimental and predicted activity values of training and test set compounds are depicted in Table 1. Figure 5 (A, B) depicts the correlation of actual and predicted activity values of the training and the test set compounds.

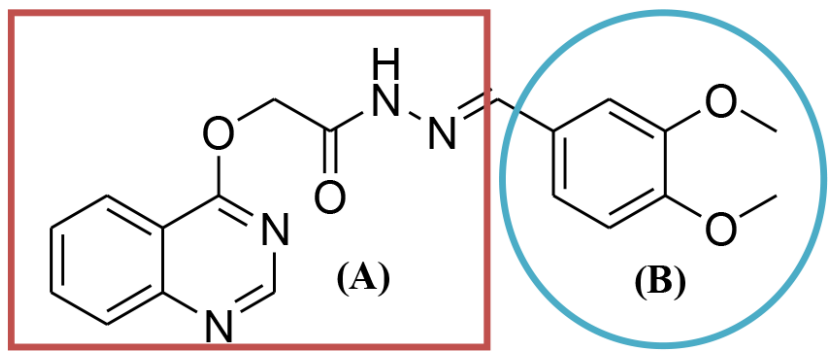

Figure 6: Compound 20 bifurcated into two regions (A, B).

\section{QSAR visualization}

3D Contour maps are the important features of the comparative molecular field analysis (CoMFA) and comparative molecular similarity indices analysis (CoMSIA). These contour maps are derived when there are changes in the molecular fields. The 3D space contour maps surrounding the compounds were derived for CoMFA as well as CoMSIA model. Based on the contour maps study, modification can be done for the improvement of the inhibitory effect and to optimize quinazoline compounds as epidermal growth factor receptor inhibitors. Most active compound bifurcated in two regions for understanding of contour maps surrounding the molecule (Figure 6).

\section{Contour maps of CoMFA}

Contour maps of steric and electrostatic fields for most active compound $20\left(\mathrm{IC}_{50}=232.54 \mathrm{nM}\right)$ are depicted in Figure 7. Style of the contour was set as "transparent" for the precise understanding of contour surrounding the molecule. In the Figure 7(A), green-colored contour indicates the steric groups are favored for the biological activity, while yellow-colored contour indicates the steric groups are not favored for the activity. Here, large green colored contour was observed in the $\mathrm{B}$ area in the phenyl ring at the meta position. It suggests that bulky and hydrophobic functional groups at this position leads to an enhancement of the biological activity. This was observed in compound $8\left(\mathrm{IC}_{50}=294.76\right.$ $\mathrm{nM})$ and $11\left(\mathrm{IC}_{50}=311.80 \mathrm{nM}\right)$ where, bulky groups like $-\mathrm{CH} 3$ and $-\mathrm{F}$ were present. So, this compounds show very good inhibitory activity against EGFR. This was also compared with the activity data of compound 7 $\left(\mathrm{IC}_{50}=426.47 \mathrm{nM}\right)$ and $23\left(\mathrm{IC}_{50}=453.78 \mathrm{nM}\right)$ in which un-substituted phenyl ring was present; so, the significant decrease in the biological activity was observed. Further, in the B region at the para position of the phenyl ring small green contour surrounded by the large yellow contour were observed. This suggests that the steric occupancy would enhance the biological effect where the size of the substituent is not too large. 


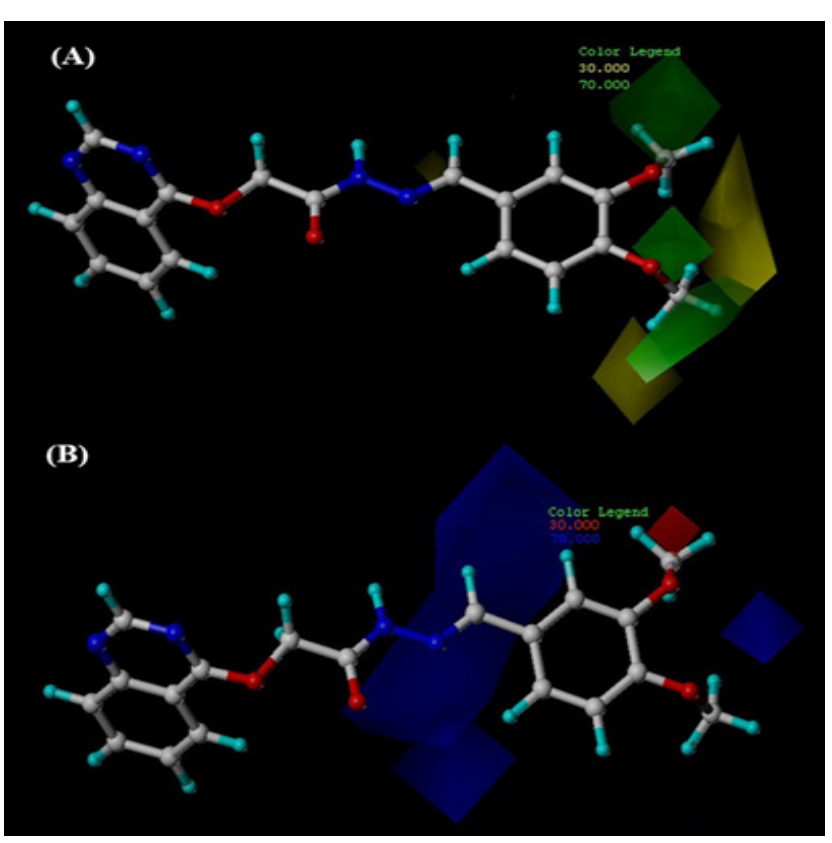

Figure 7: CoMFA (StDev ${ }^{*}$ Coeff) contour maps of steric (A) and electrostatic (B) fields for compound 20.

This is also clear from the activity data of compounds $2\left(\mathrm{IC}_{50}=330.64 \mathrm{nM}\right), 3\left(\mathrm{IC}_{50}=378.73 \mathrm{nM}\right)$ and 4 $\left(\mathrm{IC}_{50}=355.61 \mathrm{nM}\right)$ where, small bulky groups were present at this position.

Contour map of electrostatic field generated from the CoMFA analysis is depicted in the Figure 7(B). Bluecolored contour represents the region of high electrostatic tolerance while, red-colored contour represents low electrostatic tolerance. Here, blue contour was observed in $\mathrm{B}$ region at ortho position of the phenyl ring which revealed that the incorporation of electropositive group at this place leads to enhancement of the biological activity. This was clear from the biological activity data of compound $18\left(\mathrm{IC}_{50}=345.07\right)$ where, presence of electropositive methyl group showed potent biological activity. Further, it was also revealed from the comparison of biological activity data of compounds 14, 15 and 16 with compounds 17, 18 and 7. The compounds with electronegative functional groups like $-\mathrm{F},-\mathrm{Cl}$ and $-\mathrm{Br}$ have minimal biological activity and potency order was also observed as $\mathrm{F}<\mathrm{Cl}<\mathrm{Br}$. So, it was observed that as the electronegativity decreases, the biological activity of compounds increases. Further, very small red contour was observed in the B region at meta position of phenyl group, which suggests that the negatively charged group at this position enhances the biological activity. This was clear from the activity of compound $11\left(\mathrm{IC}_{50}=311.80\right)$, where electronegative $-\mathrm{F}$ was present as functional group. So, it showed moderate biological activity against EGFR.

\section{Contour maps of CoMSIA}

Steric and electrostatic contour maps of CoMSIA were similar to those observed in the CoMFA analysis. Here, the potent quinazoline derivative (compound 20) was chosen for generation of the contour maps. Hydrophobic, H-bond donor and $\mathrm{H}$-bond acceptor contour maps developed from CoMSIA analysis are represented in Figure 8. CoMSIA hydrophobic plot is characterized by yellow and white colored contours plots. Yellow colored contour suggests that the hydrophobic substituent increases the biological activity while white contour suggests that the hydrophilic substituent increases the biological activity. Here, in Figure 8 (C) small yellow colored contour was observed in $\mathrm{B}$ region at the para position of phenyl group which indicates that the incorporation of the hydrophobic substituent at this position leads to enhancement of the biological effect. This is also supported by the activity data of compounds $2\left(\mathrm{IC}_{50}=330.64\right), 3\left(\mathrm{IC}_{50}=378.73 \mathrm{nM}\right)$ and $4\left(\mathrm{IC}_{50}=\right.$ $355.61 \mathrm{nM})$ in which hydrophobic substituents were present at para position of phenyl ring. Further, white contour was observed in the B region near ortho position of phenyl group which indicates that hydrophilic groups at this place may enhance the biological activity. H-bond donor contour map generated by CoMSIA analysis is represented in Figure 8(D). H-bond donor contours are characterized by cyan and purple color. Cyan contour suggests that $\mathrm{H}$-bond donor substituents are favored, while purple contour suggest that H-bond donor groups disfavored for inhibitory activity. Here, in Figure 8 (E) a large cyan contour was observed in $\mathrm{B}$ region at the para position of phenyl ring which suggests that $\mathrm{H}$-bond donor groups in this region increase the inhibitory activity. This is also evident from the biological activity data of least active compound 6 from the entire series in which $\mathrm{H}$-bond withdrawing $-\mathrm{NO}_{2}$ substituent was present as a functional group. This leads to the significant decrease in the biological activity. This was also supported by comparison of the biological activity data of unsubstituted phenyl ring (compound 7) and compound with H-bond withdrawing substituent (Compound 6).

$\mathrm{H}$-bond acceptor contours generated from CoMSIA analysis is represented in Figure 8 (E). Acceptor field represents magenta (favored) and red (disfavoured) contour maps. Here, in Figure 8 (E) near B region at ortho position of phenyl ring, a red contour was observed which suggest that the incorporation of $\mathrm{H}$-bond acceptor at this place disfavoured for biological activity. While red contour near $\mathrm{N}$ atom in $\mathrm{B}$ region indicates that $\mathrm{H}$-bond acceptor at this place may enhance the biological effect against EGFR. Structure finding from 3D-QSAR study 


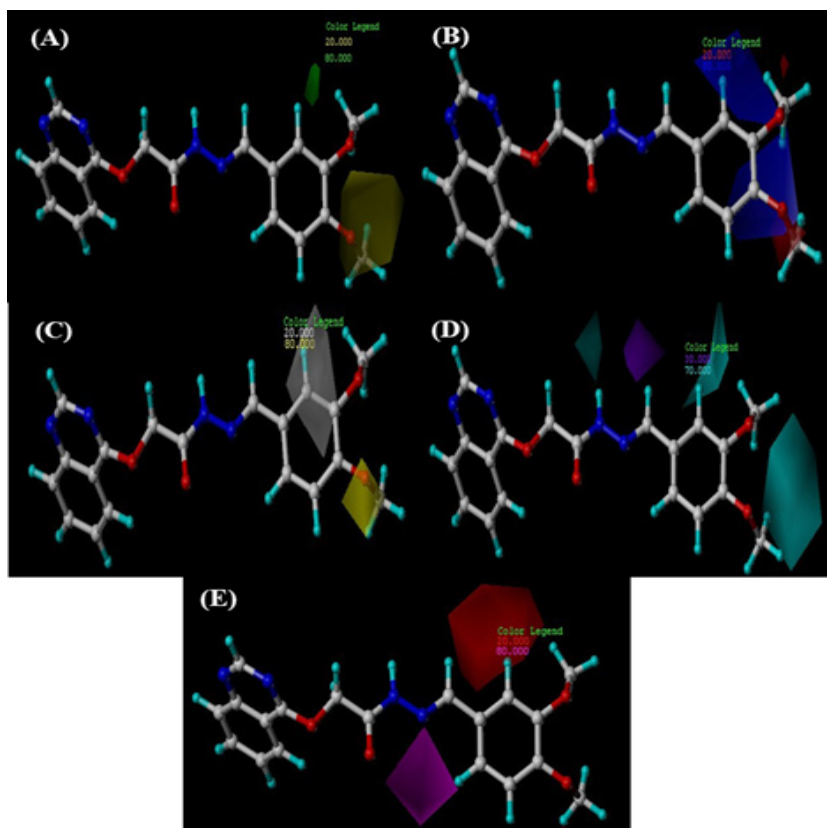

Figure 8: CoMSIA (StDev*Coeff) contour maps of steric (A), electrostatic field (B), Hydrophobic (C), H-bond donor (D) and H-bond acceptor fields (E) for compound 20.

are represented in Figure 9. Contour maps generated from comparative molecular field analysis (CoMFA) and comparative molecular similarity indices analysis (CoMSIA) provide sufficient information for the understanding of the correlation between the structural parameter of quinazoline derivatives with its biological activity againstepidermal growth factor receptor(EGFR).

\section{Docking simulation}

Docking simulation was carried out to gain the information regarding interaction of ligands at the site of EGFR receptor. All the ligands were docked to the receptor using Surflex-Dock module from SYBYL-X software. The Surflex docking scores of all quinazoline derivatives are depicted in Table 1. Results show that there is a precise correlation between observed biological activity and the docking results. Docking interaction of standard drug erlotinib, active compound 17 (Docking score- 8.3652, EGFR IC $\left.{ }_{50}=245.35 \mathrm{nM}\right)$ and compound 20 (Docking score- 6.7431, EGFR IC (D0 $_{2}=232.54$ $\mathrm{nM})$ are depicted in Figure 10, 11 and 12 respectively. Both the inhibitors were situated at the same site similar to that of the standard drug erlotinib. Compound 17 interacts with Met769 amino acid via hydrogen bond. While erlotinib also shows interaction with Met769 amino acid via H-bond. The docking score indicates a summary of all the types of interactions. Moreover, compound 17 shows very high docking score along with good penetration at the active site of receptor even

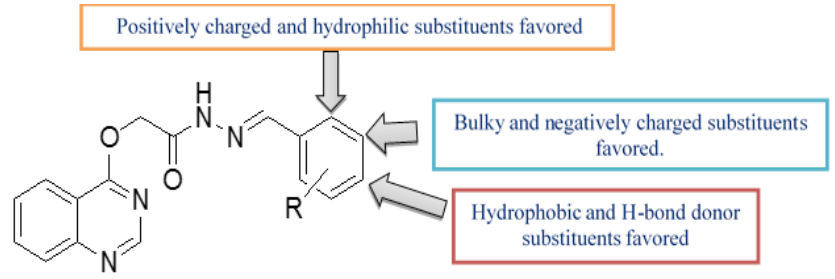

Figure 9: Structure finding from 3D-QSAR study.

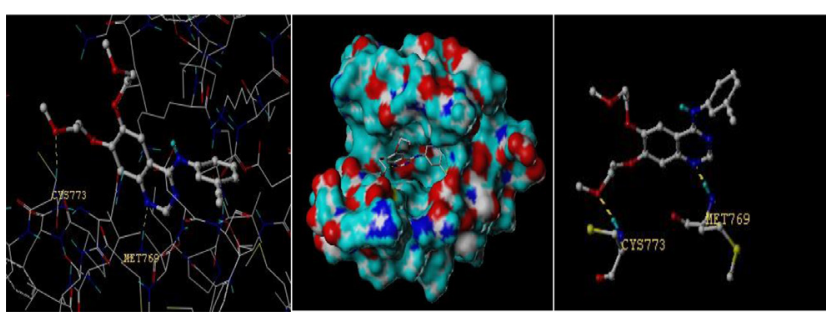

Figure 10: Docked view of approved EGFR receptor inhibitor erlotinib with receptor (Docking score- 7.699).

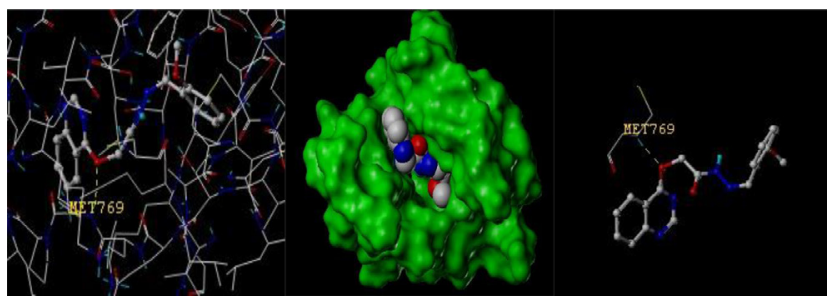

Figure 11: Docked view of compound 17 with receptor (Docking score- 8.3652, EGFR IC ${ }_{50}=245.35 \mathrm{nM}$ ).

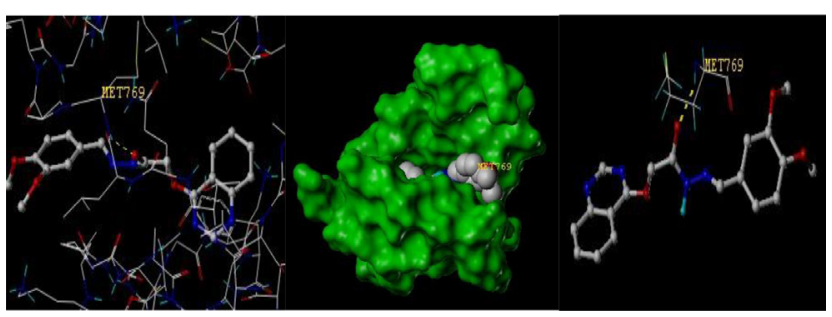

Figure 12: Docked view of compound 20 with receptor (Docking score- 6.7431, EGFR IC ${ }_{50}=232.54 \mathrm{nM}$ ).

as compare to the standard drug erlotinib. Majority of compounds shows good interaction with the active site of the receptor with better penetration efficacy.

\section{Results of Pharmacokinetic (ADMET) and molecular properties prediction of quinazoline derivatives}

All the quinazoline derivatives were evaluated (Lipinski's rule of five) for drug-like characteristics. The molecular weights of compounds were found in between 320 to 401. It plays important role in biological activity with respect to penetration at the target site. Lipophilicity 


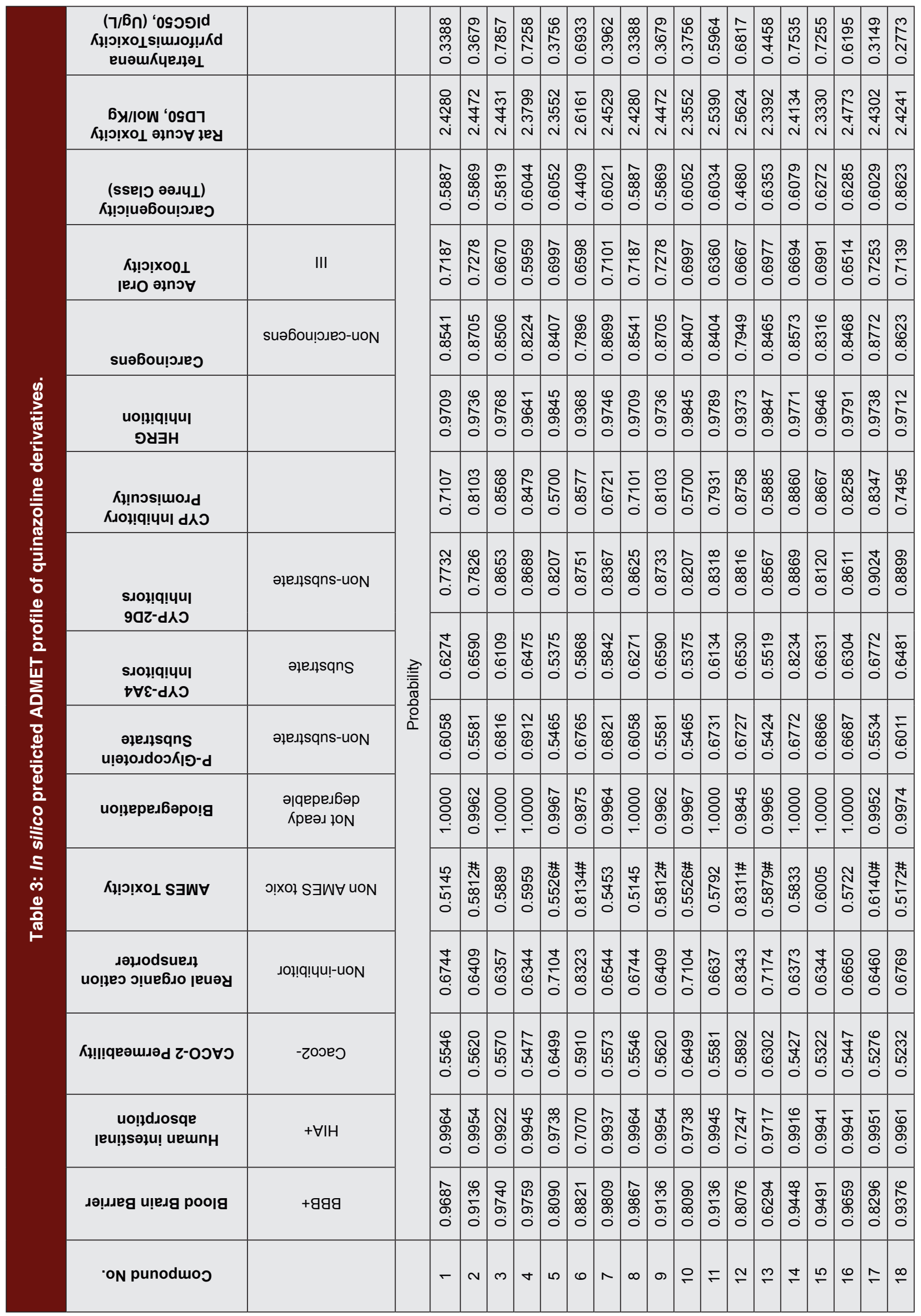




\begin{tabular}{|c|c|c|c|c|c|c|c|}
\hline 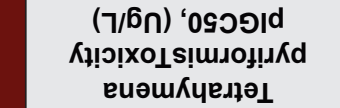 & & $\begin{array}{l}\infty \\
\stackrel{p}{\rho} \\
m \\
0 \\
0\end{array}$ & 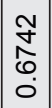 & $\mid \begin{array}{l}\infty \\
0 \\
0 \\
0 \\
0\end{array}$ & $\begin{array}{l}m \\
\delta \\
0 \\
0 \\
0\end{array}$ & $\begin{array}{l}\hat{0} \\
\infty \\
0 \\
0 \\
0\end{array}$ & 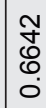 \\
\hline 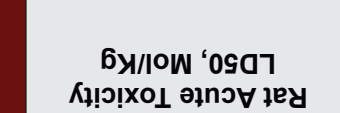 & 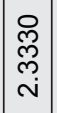 & $\begin{array}{c}\stackrel{N}{N} \\
\stackrel{+}{\sim} \\
\sim\end{array}$ & 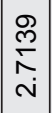 & $\begin{array}{c}\hat{D} \\
\text { N } \\
\text { N }\end{array}$ & $\begin{array}{c}\text { O } \\
\stackrel{D}{+} \\
\text { ․ }\end{array}$ & 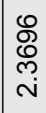 & 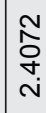 \\
\hline 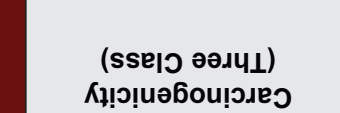 & \begin{tabular}{c}
$\mathfrak{N}$ \\
\multirow{N}{0}{} \\
$\vdots$ \\
0
\end{tabular} & 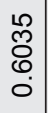 & 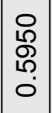 & $\begin{array}{l}0 \\
0 \\
6 \\
0\end{array}$ & $\begin{array}{c}0 \\
\text { o } \\
\infty \\
0 \\
0 \\
0\end{array}$ & $\begin{array}{l}0 \\
0 \\
0 \\
0 \\
0 \\
0\end{array}$ & 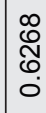 \\
\hline 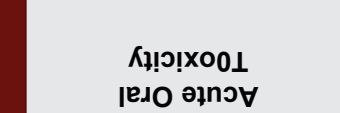 & \begin{tabular}{|c|}
$\overline{8}$ \\
$\mathscr{8}$ \\
0 \\
0
\end{tabular} & $\begin{array}{l}0 \\
\stackrel{0}{0} \\
\vdots \\
0\end{array}$ & $\begin{array}{c}\stackrel{\sim}{\sim} \\
\underset{\circlearrowleft}{0} \\
\dot{0}\end{array}$ & $\begin{array}{l}10 \\
\text { வ } \\
0 \\
0\end{array}$ & $\begin{array}{l}\infty \\
0 \\
\mathscr{8} \\
\bullet \\
0\end{array}$ & $\begin{array}{l}0 \\
\tilde{N} \\
0 \\
0 \\
0\end{array}$ & $\begin{array}{l}0 \\
0 \\
0 \\
0 \\
0 \\
0\end{array}$ \\
\hline suə6ou!̣eว & $\begin{array}{c}0 \\
\tilde{m} \\
\infty \\
0\end{array}$ & 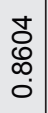 & $\begin{array}{c}0 \\
\text { fे } \\
\infty \\
0 \\
0\end{array}$ & $\begin{array}{c}\tilde{n} \\
\tilde{N} \\
\\
0\end{array}$ & $\begin{array}{c}\text { क } \\
\stackrel{N}{\infty} \\
\infty \\
0\end{array}$ & 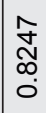 & $\begin{array}{l}\text { L } \\
\text { م } \\
\infty \\
0 \\
0\end{array}$ \\
\hline 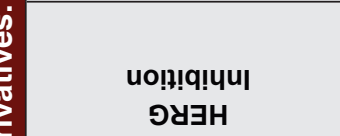 & \begin{tabular}{|c|}
0 \\
\multirow{+}{0}{} \\
$\mathscr{0}$ \\
$\dot{0}$
\end{tabular} & $\begin{array}{l}\frac{10}{\infty} \\
\infty \\
0 \\
0\end{array}$ & $\begin{array}{l}0 \\
\infty \\
\infty \\
o \\
0\end{array}$ & $\mid \begin{array}{l}\ddagger \\
0 \\
0 \\
0 \\
0 \\
0\end{array}$ & $\mid \begin{array}{l}\infty \\
0 \\
\mathscr{Q} \\
\mathscr{0} \\
0\end{array}$ & $\begin{array}{l}- \\
0 \\
0 \\
o \\
0\end{array}$ & 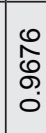 \\
\hline $\begin{array}{l}\text { Kł!nos!̣uodd } \\
\text { Клoł!q!पul dᄉว }\end{array}$ & \begin{tabular}{|l|}
0 \\
0 \\
0 \\
$\infty$ \\
0 \\
0
\end{tabular} & 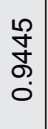 & 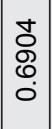 & 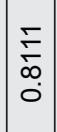 & $\begin{array}{c}N \\
N \\
N \\
0\end{array}$ & 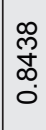 & $\begin{array}{l}1 \\
0 \\
0 \\
1 \\
\infty \\
0 \\
0\end{array}$ \\
\hline s.oł!q!yu| & $\left|\begin{array}{c}0 \\
\square \\
\infty \\
\infty \\
0\end{array}\right|$ & $\begin{array}{l}\stackrel{0}{f} \\
\text { Jे } \\
0\end{array}$ & \begin{tabular}{|c|}
$\infty$ \\
0 \\
0 \\
$\infty$ \\
0 \\
0
\end{tabular} & 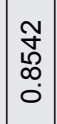 & $\left|\begin{array}{l}- \\
\varnothing \\
0 \\
0 \\
0\end{array}\right|$ & $\begin{array}{l}\mathbb{N} \\
0 \\
0 \\
0 \\
0 \\
0\end{array}$ & $\begin{array}{c}0 \\
\mathbb{N} \\
\infty \\
0 \\
0\end{array}$ \\
\hline $\begin{array}{l}\text { s.oł!q!पu। } \\
\triangleright \forall \varepsilon-d \lambda \supset\end{array}$ & $\begin{array}{l}\check{\tilde{O}} \\
0 \\
0 \\
0\end{array}$ & $\mid \begin{array}{l}\infty \\
0 \\
N \\
0 \\
0\end{array}$ & \begin{tabular}{|l|}
$\mathscr{m}$ \\
$\bar{m}$ \\
\\
0
\end{tabular} & $\begin{array}{l}0 \\
0 \\
0 \\
0 \\
0 \\
0\end{array}$ & 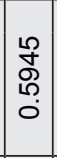 & $\begin{array}{l}\infty \\
0 \\
0 \\
10 \\
0 \\
0\end{array}$ & $\begin{array}{l}m \\
\vdots \\
\vdots \\
0 \\
0\end{array}$ \\
\hline 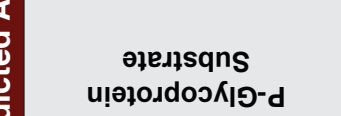 & $\begin{array}{l}0 \\
0 \\
\mathscr{D} \\
0 \\
0 \\
0\end{array} \mid$ & $\begin{array}{l}0 \\
0 \\
\text { ก } \\
\text { مִ } \\
0\end{array}$ & \begin{tabular}{|l|}
$\stackrel{N}{ }$ \\
$\stackrel{\delta}{0}$ \\
$\stackrel{0}{0}$
\end{tabular} & $\begin{array}{c}\tilde{N} \\
\text { గొ } \\
0 \\
0\end{array}$ & 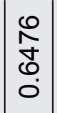 & O̊ & 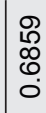 \\
\hline ио!џередбәро!я & $\begin{array}{l}8 \\
8 \\
8 \\
\end{array}$ & 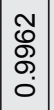 & ষ্ণ & 음 & 응 & ৪ & 응 \\
\hline 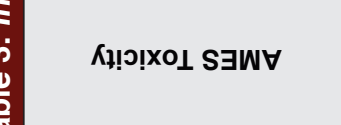 & \begin{tabular}{|l|}
1 \\
0 \\
0 \\
0 \\
0 \\
0
\end{tabular} & 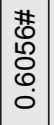 & $\mid \begin{array}{c}0 \\
0 \\
0 \\
0 \\
0 \\
0\end{array}$ & $\begin{array}{c}1 \\
0 \\
5 \\
0 \\
0\end{array}$ & $\begin{array}{c}\text { న్ } \\
\text { W్ } \\
\text { [م } \\
0\end{array}$ & 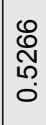 & $\begin{array}{l}8 \\
0 \\
0 \\
0 \\
0 \\
0\end{array}$ \\
\hline 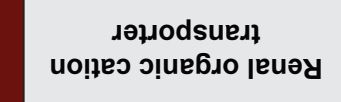 & 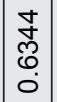 & $\mid$ & $\mid \begin{array}{c}m \\
\stackrel{m}{2} \\
0 \\
0 \\
0\end{array}$ & $\begin{array}{l}\mathscr{8} \\
\mathscr{8} \\
0 \\
0 \\
0\end{array}$ & $\begin{array}{l}\tilde{m} \\
\ddot{0} \\
\dot{0}\end{array}$ & $\begin{array}{l}\text { ठ } \\
0 \\
0 \\
0 \\
0\end{array}$ & $\begin{array}{l}\infty \\
0 \\
0 \\
0 \\
0\end{array}$ \\
\hline 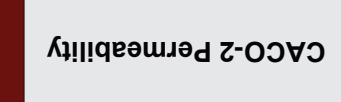 & N్ & $\begin{array}{l}0 \\
\text { L } \\
0 \\
0 \\
0 \\
0\end{array}$ & $\mid \begin{array}{l}\bar{\infty} \\
0 \\
\omega \\
0 \\
0\end{array}$ & $\begin{array}{l}\tilde{R} \\
0 \\
0 \\
0 \\
0\end{array}$ & 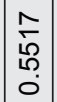 & $\underset{\check{\sigma}}{\check{\sigma}}$ & 立 \\
\hline $\begin{array}{c}\text { uo!jdıosqe } \\
\text { ןeu!fsəłu! uewnh }\end{array}$ &  & $\mid \begin{array}{l}0 \\
0 \\
0 \\
0 \\
0\end{array}$ & ৪ & 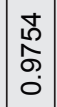 & 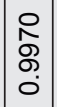 &  & $\begin{array}{l}\text { N } \\
\text { S. } \\
\text { S. } \\
\text { on }\end{array}$ \\
\hline دəןıرeg u!esg poolg & 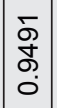 & \begin{tabular}{|l|}
$\tilde{m}$ \\
$\infty$ \\
$\tilde{0}$ \\
0 \\
0
\end{tabular} & $\begin{array}{l}0 \\
\infty \\
\infty \\
o \\
0\end{array}$ & $\mid \begin{array}{c}\infty \\
\stackrel{f}{f} \\
0 \\
0 \\
0\end{array}$ & 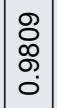 & $\begin{array}{l}\qquad 0 \\
0 \\
0 \\
0 \\
0\end{array}$ & 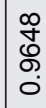 \\
\hline 'ON punoduos & () & $\stackrel{\sim}{\sim}$ & $\bar{N}$ & $\approx$ & N & $\stackrel{4}{ \pm}$ & $\stackrel{\sim}{\sim}$ \\
\hline
\end{tabular}

$(\log \mathrm{P})$ and Topological Polar Surface Area (TPSA) play important role in permeability of compounds via plasma membrane. Total surface areas occupied by oxygen and nitrogen atoms and hydrogen attached to these molecules is expressed as TPSA value. Here, $\log \mathrm{P}$ values of quinazoline derivatives were less than 5. While TPSA value was found to be less than 150 . It was reported that the bioavailability of the com pounds will be very high if TPSA value $\leq 140 \dot{A}$ and rotational bonds $\leq 10 .^{37}$ Further ADMET properties of all the quinazoline derivatives were calculated using admetSAR software. ${ }^{38}$ Different absorption related parameter i.e. BBB penetration, HIA, Caco-2 Permeability, Renal Organic Cation Transporter etc. were calculated and reported in Table 3. Cytochrome enzyme family was involved in the process of metabolism as well as drug-drug interaction process. With this fact, different metabolism related parameters such as CYP450 2D6 Substrate; CYP450 3A4 Substrate; CYP Inhibitory Promiscuity etc. were also reported. The molecular properties of compounds were also responsible for tumorigenic or carcinogenic potential. Carcinogenicity, acute oral toxicity and acute dose toxicity in rat $\left(\mathrm{LD}_{50}\right)$ are also depicted in Table 3. AdmetSAR results reveal that, quinazoline derivatives can be easily absorbed from the intestine with remarkable biodegradable characteristics. Except for few compounds (2, 5, 6, 9, 10, $12,13,17)$, the majority of compounds did not show AMES toxicity. Moreover, quinazoline derivatives did not show any carcinogenic or tumorigenic property.

\section{CONCLUSION}

EGFR signaling inhibitors are highly promising therapeutic class for the treatment of Cancer. Small molecule receptor tyrosine kinase inhibitors and monoclonal antibody $(\mathrm{mAb})$ class show potent activity against solid tumours. Mutation in EGFR leads to resistance against current cancer treatment. Therefore, there is always a constant need to discover new inhibitors. To support that, we undertook ligand based drug design approach using QSAR by CoMFA and CoMSIA. PLS analysis was undertaken for the correlation of the structure characteristics of quinazoline derivatives with its biological activity. Results obtained from CoMFA and CoMSIA analysis were found satisfactory. Predictive power of CoMFA analysis was found to be better than CoMSIA analysis. The contour maps analysis suggests that at the terminal phenyl ring; positively charged substituents at ortho position, bulky with negatively charged substituents at meta position and the hydrophobic substituents at para position enhances the biological activity against 


\begin{tabular}{|c|c|c|c|c|c|c|c|}
\hline \multirow[b]{2}{*}{$\begin{array}{c}\text { Compound } \\
\text { No. }\end{array}$} & \multicolumn{4}{|c|}{ Lipinski Properties } & \multirow[b]{2}{*}{$\begin{array}{l}\text { Lipinski } \\
\text { Violation }\end{array}$} & \multirow[b]{2}{*}{$\begin{array}{c}\text { Molar } \\
\text { Refractivity }\end{array}$} & \multirow[b]{2}{*}{ TPSA } \\
\hline & $\begin{array}{l}\text { Hydrogen } \\
\text { Bond Donner }\end{array}$ & $\begin{array}{l}\text { Hydrogen } \\
\text { Bond } \\
\text { Acceptor }\end{array}$ & $\begin{array}{c}\text { Molecular } \\
\text { Weight (g/ } \\
\text { Mol) }\end{array}$ & $\log P$ & & & \\
\hline 1 & 1 & 6 & 320 & 2.858 & 0 & 91.783 & 76.47 \\
\hline 2 & 1 & 7 & 336 & 2.558 & 0 & 93.309 & 85.70 \\
\hline 3 & 1 & 6 & 385 & 3.312 & 0 & 94.517 & 76.47 \\
\hline 4 & 1 & 6 & 340 & 3.203 & 0 & 91.827 & 76.47 \\
\hline 5 & 1 & 7 & 322 & 2.255 & 0 & 88.840 & 96.70 \\
\hline 6 & 1 & 7 & 351 & 2.981 & 0 & 95.639 & $122.2 \mathrm{~s}$ \\
\hline 7 & 1 & 6 & 306 & 2.549 & 0 & 86.817 & 76.47 \\
\hline 8 & 1 & 6 & 320 & 2.858 & 0 & 91.783 & 76.47 \\
\hline 9 & 1 & 7 & 336 & 2.558 & 0 & 93.309 & 85.70 \\
\hline 10 & 2 & 7 & 322 & 2.255 & 0 & 88.840 & 96.70 \\
\hline 11 & 1 & 6 & 324 & 2.688 & 0 & 86.775 & 76.47 \\
\hline 12 & 1 & 7 & 351 & 2.981 & 0 & 95.639 & 122.29 \\
\hline 13 & 1 & 7 & 322 & 2.255 & 0 & 88.840 & 96.70 \\
\hline 14 & 1 & 6 & 385 & 3.312 & 0 & 94.517 & 76.47 \\
\hline 15 & 1 & 6 & 340 & 3.203 & 0 & 91.827 & 76.47 \\
\hline 16 & 1 & 6 & 324 & 2.688 & 0 & 86.775 & 76.47 \\
\hline 17 & 1 & 7 & 336 & 2.558 & 0 & 93.309 & 85.70 \\
\hline 18 & 1 & 6 & 320 & 2.858 & 0 & 91.783 & 76.47 \\
\hline 19 & 1 & 6 & 375 & 3.856 & 0 & 96.831 & 76.47 \\
\hline 20 & 1 & 8 & 366 & 2.567 & 0 & 99.80 & 94.93 \\
\hline 21 & 1 & 6 & 374 & 3.568 & 0 & 91.81 & 76.47 \\
\hline 22 & 2 & 7 & 356 & 2.908 & 0 & 93.85 & 96.70 \\
\hline 23 & 1 & 6 & 332 & 3.214 & 0 & 96.74 & 76.47 \\
\hline 24 & 1 & 7 & 401 & 3.017 & 0 & 96.54 & 96.70 \\
\hline 25 & 1 & 6 & 358 & 3.342 & 0 & 91.78 & 76.47 \\
\hline
\end{tabular}

epidermal growth factor receptor. Moreover, molecular docking simulation on X-RAY crystal structure of EGFR provides insight into the structural requirements of receptor. Most active compounds, as well as standard drug erlotinib have interaction with Met769 amino acid via hydrogen bonding. Further, ADMET results also show that the reported quinazoline derivatives have a significant pharmacokinetic profile to become a potential drug candidate. Results of the QSAR and molecular docking simulation may be used for discovery and development of new quinazoline derivatives as selective EGFR inhibitors as anticancer agents.

\section{AUTHOR CONTRIBUTIONS}

Both the authors, Siddharth J. Modi and Vithal M. Kulkarni have approved the final version of the manuscript.

\section{ACKNOWLEDGEMENT}

The authors are grateful to Dr. S.S. Kadam, Chancellor, Bharati Vidyapeeth (Deemed to be University), Pune and Dr. K. R. Mahadik, Principal, Poona College of Pharmacy, Pune for their encouragement.

\section{CONFLICT OF INTEREST}

The authors declare no conflict of interest pertaining to this manuscript.

\section{ABBREVIATIONS}

EGFR: Epidermal Growth Factor Receptor; RTK: Receptor Tyrosine Kinase; QSAR: Quantitative Structure Activity Relationships; CoMFA: Comparative Molecular Field Analysis; CoMSIA: Comparative Molecular Similarity Indices Analysis; PLS: Partial Least Square Analysis; LOO: Leave One Out; ONC: Optimum 
Number of Components; GH: Gasteiger Huckel; $\mathbf{r}^{2}$ ncv Non-cross validation correlation coefficient; $\mathbf{r}^{2}{ }_{\text {pred }}$ : Predictive correlation coefficient; $\mathbf{q}^{2}$ : Cross validation correlation coefficient; SEE: Standard Error of Estimate; F value: Fisher's value; PDB: Protein Data Bank; BBB+: Blood-Brain Barrier; HIA: Human Intestinal Absorption; HERG: Human Ether-a-go-go-Related Gene; TPSA: Topological Polar Surface Area.

\section{REFERENCES}

1. Linggi B, Carpenter G. ErbB receptors: new insights on mechanisms and biology. Trends in cell Biology. 2006;16(12):649-56.

2. Yarden $\mathrm{Y}$, Sliwkowski MX. Untangling the ErbB signalling network. Nature Reviews Molecular Cell Biology. 2001;2(2):127.

3. Hynes NE, Lane HA. ERBB receptors and cancer: the complexity of targeted inhibitors. Nature Reviews Cancer. 2005;5(5):341.

4. Burgess AW, Cho HS, Eigenbrot C, Ferguson KM, Garrett TP, Leahy DJ, et al. An open-and-shut case?. Recent insights into the activation of EGF/ErbB receptors. Molecular cell. 2003;12(3):541-52.

5. Olayioye MA, Neve RM, Lane HA, Hynes NE. The ErbB signaling network: receptor heterodimerization in development and cancer. The EMBO Journal. 2000;19(13):3159-67.

6. Yarden Y. The EGFR family and its ligands in human cancer: signalling mechanisms and therapeutic opportunities. European Journal of Cancer. 2001;37:3-8.

7. Normanno N, Bianco C, De Luca A, Maiello MR, Salomon DS. Target-based agents against ErbB receptors and their ligands: a novel approach to cancer treatment. Endocrine-related Cancer. 2003;10(1):1-21.

8. Carraway III KL, Weber JL, Unger MJ, Ledesma J, Yu N, Gassmann M, et al. Neuregulin-2, a new ligand of ErbB3/ErbB4-receptor tyrosine kinases. Nature. 1997;387(6632):512-6.

9. Chang H, Riese II DJ, Gilbert W, Stern DF, McMahan UJ. Ligands for ErbB-family receptors encoded by a neuregulin-like gene. Nature. 1997;387(6632):509.

10. Harari D, Tzahar E, Romano J, Shelly M, Pierce JH, Andrews GC, et al. Neuregulin-4: a novel growth factor that acts through the ErbB-4 receptor tyrosine kinase. Oncogene. 1999;18(17):2681.

11. Normanno N, De Luca A, Bianco C, Strizzi L, Mancino M, Maiello MR, et al. Epidermal growth factor receptor (EGFR) signaling in cancer. Gene. 2006;366(1):2-16.

12. Walker F, Abramowitz L, Benabderrahmane D, Duval X, Descatoire V, Hénin D, et al. Growth factor receptor expression in anal squamous lesions: modifications associated with oncogenic human papillomavirus and human immunodeficiency virus. Human Pathology. 2009;40(11):1517-27.

13. Mok TS, Wu YL, Thongprasert S, Yang CH, Chu DT, Saijo N, et al. Gefitinib or carboplatin-paclitaxel in pulmonary adenocarcinoma. New England Journal of Medicine. 2009;361(10):947-57.

14. Cappuzzo F, Ciuleanu T, Stelmakh L, Cicenas S, Szczésna A, Juhász E, et al. Erlotinib as maintenance treatment in advanced non-small-cell lung cancer: a multicentre, randomised, placebo-controlled phase 3 study. The Lancet Oncology. 2010;11(6):521-9.

15. Yap TA, Vidal L, Adam J, Stephens P, Spicer J, Shaw H, Ang J, et al. Phase I trial of the irreversible EGFR and HER2 kinase inhibitor BIBW 2992 in patients with advanced solid tumors. Journal of Clinical Oncology. 2010;28(25):3965-72.

16. Minkovsky N, Berezov A. BIBW-2992, a dual receptor tyrosine kinase inhibitor for the treatment of solid tumors. Current Opinion in Investigational Drugs (London, England: 2000). 2008;9(12):1336-46

17. Huang WS, Liu S, Zou D, Thomas M, Wang Y, Zhou T, et al. Discovery of brigatinib (AP26113), a phosphine oxide-containing, potent, orally active inhibitor of anaplastic lymphoma kinase. Journal of Medicinal Chemistry. 2016;59(10):4948-64.
18. Gandhi L, Besse B, Mazieres J, Waqar S, Cortot A, Barlesi F, et al. MA04. 02 neratinibttemsirolimus in HER2-mutant lung cancers: an international, randomized phase II study. Journal of Thoracic Oncology. 2017;12(1):S358-9.

19. Burris HA. Dual kinase inhibition in the treatment of breast cancer: initial experience with the EGFR/ErbB-2 inhibitor lapatinib. The Oncologist. 2004;9(Suppl 3):10-5.

20. Gibson TB, Ranganathan A, Grothey A. Randomized Phase III Trial Results of Panitumumab, a Fully Human Anti-Epidermal Growth Factor Receptor Monoclonal Antibody, in Metastatic Colorectal Cancer. Clinical Colorectal Cancer. 2006;6(1):29-31.

21. Ramakrishnan MS, Eswaraiah A, Crombet T, Piedra P, Saurez G, Iyer H, et al. Nimotuzumab, a promising therapeutic monoclonal for treatment of tumors of epithelial origin. InMAbs. 2009;1(1):41-8.

22. Graeven U, Kremer B, Südhoff T, Killing B, Rojo F, Weber D, et al. Phase I study of the humanised anti-EGFR monoclonal antibody matuzumab (EMD 72000 ) combined with gemcitabine in advanced pancreatic cancer. British Journal of Cancer. 2006;94(9):1293.

23. Morgillo F, Della CCM, Fasano M, Ciardiello F. Mechanisms of resistance to EGFR-targeted drugs: lung cancer. ESMO Open. 2016;1(3):e000060.

24. Lu L, Zhao TT, Liu TB, Sun WX, Xu C, Li DD, et al. Synthesis, Molecular modeling and biological evaluation of 4-alkoxyquinazoline derivatives as novel inhibitors of VEGFR2. Chemical and Pharmaceutical Bulletin. 2016;64(11):1570-5.

25. Cramer RD, Patterson DE, Bunce JD. Comparative molecular field analysis (CoMFA). 1. Effect of shape on binding of steroids to carrier proteins. Journal of the American Chemical Society. 1988;110(18):5959-67.

26. Klebe $G$, Abraham $U$, Mietzner T. Molecular similarity indices in a comparative analysis (CoMSIA) of drug molecules to correlate and predict their biological activity. Journal of Medicinal Chemistry. 1994;37(24):4130-46.

27. Khanfar MA, Youssef DT, EI Sayed KA. 3D-QSAR studies of latrunculinbased actin polymerization inhibitors using CoMFA and CoMSIA approaches. European Journal of Medicinal Chemistry. 2010;45(9):3662-8.

28. Clark M, Cramer RD, Van ON. Validation of the general purpose Tripos 5.2 force field. Journal of Computational Chemistry. 1989;10(8):982-1012.

29. Purushottamachar P, Kulkarni VM. 3D-QSAR of N-myristoyltransferase inhibiting antifungal agents by CoMFA and CoMSIA methods. Bioorganic and Medicinal Chemistry. 2003;11(16):3487-97.

30. Buolamwini JK, Assefa H. CoMFA and CoMSIA 3D QSAR and docking studies on conformationally-restrained cinnamoyl HIV-1 integrase inhibitors: exploration of a binding mode at the active site. Journal of Medicinal Chemistry. 2002;45(4):841-52.

31. Golbraikh A, Tropsha A. Beware of q2!. Journal of Molecular Graphics and Modelling. 2002;20(4):269-76.

32. Shinde MG, Modi SJ, Kulkarni VM. QSAR and Molecular Docking of Phthalazine Derivatives as Epidermal Growth Factor Receptor (EGFR) Inhibitors. Journal of Applied Pharmaceutical Science Vol. 2017;7(04):181-91.

33. Ayoup MS, Ahmed HE, El Massry AM, Senior S, Khattab SN, Hassan SY, et al. Synthesis, Docking and Evaluation of Antimicrobial Activity of a New Series of Acyclo C-Nucleosides of 1,2,4-Triazolo [4, 3-a] quinoxaline Derivatives. Journal of Heterocyclic Chemistry. 2016;53(1):153-63.

34. Rarey M, Kramer B, Lengauer T, Klebe G. A fast flexible docking method using an incremental construction algorithm. Journal of Molecular Biology. 1996;261(3):470-89.

35. Jones G, Willett P, Glen RC, Leach AR, Taylor R. Development and validation of a genetic algorithm for flexible docking. Journal of Molecular Biology. 1997;267(3):727-48

36. Joshi SD, More UA, Pansuriya K, Aminabhavi TM, Gadad AK. Synthesis and molecular modeling studies of novel pyrrole analogs as antimycobacterial agents. Journal of Saudi Chemical Society. 2017;21(1):42-57.

37. Veber DF, Johnson SR, Cheng HY, Smith BR, Ward KW, Kopple KD. Molecular properties that influence the oral bioavailability of drug candidates. J Med Chem. 2002;45(12):2615-23.

38. Cheng F, Li W, Zhou Y, Shen J, Wu Z, Liu G, et al. AdmetSAR: a comprehensive source and free tool for assessment of chemical ADMET properties. J Chem Inf Model. 2012;52:3099-105. 


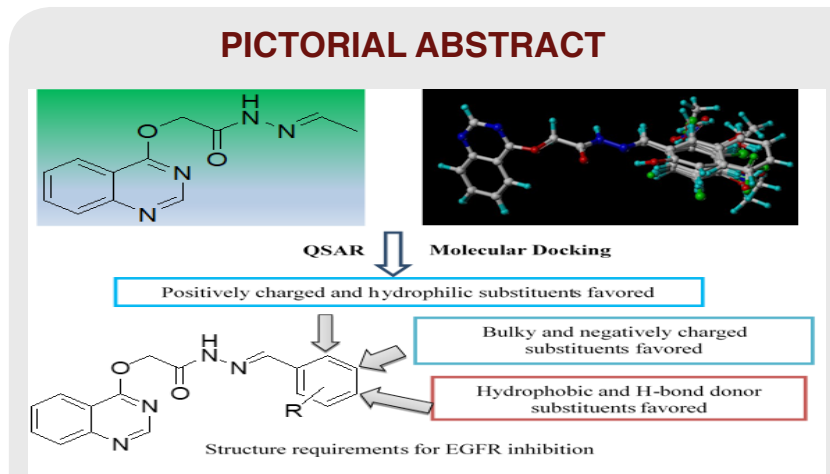

About Authors

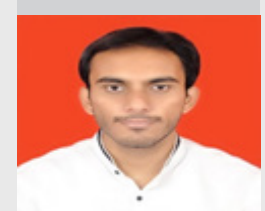

Mr. Siddharth J. Modi is research scholar for the Degree of Ph.D. in Pharmaceutical Chemistry at Poona College of Pharmacy, Pune, working under the guidance of Prof. Dr. V M. Kulkarni. He has completed B.Pharm. from Institute of Pharmacy, Nirma University, Ahmedabad. and M.Pharm. from Bharati Vidyapeeth (Deemed to be University), Pune. Jointly with his research guide, he has published 6 research papers and filed 1 patent, mainly in the area of design of novel anticancer agents. He has presented research papers in $68^{\text {th }}$ IPC, Vishakhapatnam and in $9^{\text {th }}$ International Symposium on Computational Methods in Toxicology and Pharmacology Integrating Internet Resources (CMTPI-2017), Goa where he has secured second place in the student election sponsored by Taylor \& Francis for best poster presentation. He has also been awarded IPA Pune Innovative PG Research Award-2017.

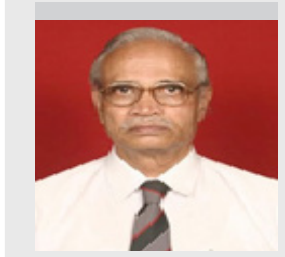

Dr. V. M. Kulkarni has a teaching experience of 42 years and research experience of 38 years. $\mathrm{He}$ is Ph.D. from University of Mumbai, Post-doctorate from Tata Institute of Fundamental Research, Mumbai and Forschunginstitut Borstel, Germany. After 6 years as a Professor in Bombay College of Pharmacy, he joined Mumbai University, Department of Chemical technology (ICT formerly UDCT) as Professor of Medicinal Chemistry and Head of Pharmaceutical Sciences and Technology Division, Mumbai-400019. During 15 years of his service here and till retirement, he received substantial research grants from UGC, AICTE, DST and also from several pharmaceutical industries such as Cipla, Dr. Reddy's labs, Unichem, Ranbaxy etc. He was consultant and advisor of several organizations. He strengthened computer aided drug design in India and introduced drug discovery methods in the several pharmaceutical industries and in many pharmacy colleges in India. His research areas include Design and Development of Drugs against Fungal, Leprosy, Inflammation, Diabetes and Cancer diseases. He has published more than 150 research papers, 20 patents and guided more than 200 Students for M.Pharm. and 48 for Ph.D. Degrees and handled about 55 sponsored Research Projects. He is popularly known as "Indian Father of OSAR". He was invited six times from the prestigious Gordon Research Conferences, USA. He has travelled almost worldwide for conferences, symposia etc. He has delivered lectures in many pharmacy colleges and CSIR labs. Recognizing his contribution in teaching and research, he was awarded "APTI-Prof. G. P. Srivastava Memorial Award" in 2017. He is also an eminent Pharmacist Awardee of IPA. Presently, he is Professor Emeritus in Poona College of Pharmacy, Bharati Vidyapeeth (Deemed to be University), Pune and active in teaching and research in the areas of Pharmaceutical Science.

Cite this article: Modi SJ, Kulkarni VM. Quinazoline Derivatives as Anticancer Agents: QSAR, Molecular Docking and In silico Pharmacokinetic Prediction. Indian J of Pharmaceutical Education and Research. 2018;52(4 Suppl 2): s309-s325. 